\title{
Some Policy Effects in Developing Economies with Dual Labor Markets
}

\author{
Vikram Kumar $^{1}$ \\ ${ }^{1}$ Department of Economics, Davidson College, Davidson, NC, USA \\ Correspondence: Vikram Kumar, Department of Economics, Davidson College, Box 6975, Davidson NC \\ 28035-6975, USA. Tel: 704-894-2265. E-mail: vikumar@davidson.edu
}

Received: September 22, 2013

Accepted: October 24, 2013

Online Published: November 26, 2013

doi:10.5539/ijef.v5n12p1

URL: http://dx.doi.org/10.5539/ijef.v5n12p1

\begin{abstract}
A central feature of developing economies is the existence of dual labor markets, with an organized formal sector usually subject to a binding wage floor, and an informal sector which pays lower wages and where entry is free. It has also been observed in the literature that the preponderance of tradable and non-tradable goods are produced in the formal and informal sectors, respectively. This paper highlights the role played by these stylized structural features in determining policy outcomes in developing economies. We consider an economy where workers employed in the informal sector face some probability of being offered a job in the high-wage formal sector but this probability increases if they do not work but actively search for such a job, i.e., there exists a job search premium. We show that the job search premium and relative size of the informal sector are key elements that affect the results of policy changes with regard to sectoral wage differentials, argue that devaluation reduces the trade balance and may be contractionary, and that policies to increase the efficiency of labor exchange have an independent effect on the real exchange rate.
\end{abstract}

Keywords: non-tradable goods, job search premium, dual labor markets, exchange rate, devaluation

\section{Introduction}

Among the common structural features of developing countries is the presence of dual labor markets. On the one hand, there exists a formal, organized sector of the economy, usually with a binding wage floor where jobs are eagerly sought and which produces the bulk of tradable goods, and on the other, an unorganized, informal sector where entry is free, wages are relatively low and which largely produces non-tradable goods. Meaningful open-economy analyses of shocks in developing countries therefore require careful consideration of the prevalence of dual labor markets with wage restrictions of partial coverage and the presence of non-traded goods.

Whatever the source of the barrier to wage arbitrage, in such an economy the persistence of a wage differential between the high-wage formal and low-wage informal sectors is consistent with a state of unemployment that is both voluntary and economically rational. Workers not employed in the formal sector may freely enter the informal sector and earn the going wage; at the same time they face some probability of obtaining a formal sector job by happenstance while employed in informal activity. Conversely, they may eschew informal employment altogether and devote their time exclusively seeking out a higher-paying formal sector job thereby increasing the probability of obtaining the formal sector job. They would do so if the opportunity cost of unemployment-the expected earnings obtainable in the informal sector-is offset by the gains resulting from the increased probability of obtaining the formal sector job. The increase in this probability reflects the existence of a 'job search premium' as articulated in Pinera and Selowsky (1978).

In this paper, such a labor market is nested in a product market framework where tradables are produced in the formal sector and non-tradables in the informal sector (See, for instance, Fiess et. al. 2010; Agénor \& Aizenman, 1999). We examine how these structural factors shape the responses of a small open developing country to policy shocks. In doing so, we specifically highlight the role of the job search premium in determining their outcomes, and this particular focus provides a point of departure from the rich literature on both small open economies and dual labor markets. For instance, Brecher (1974) is an early study of the effects of wage restrictions which did not consider non-traded goods, whereas Helpman (1977) considers both tradable and non-tradable goods but in an economy with a wage floor across both sectors, which results in involuntary unemployment. The importance of search activity in segmented labor markets is exemplified in Harris and Todaro (1970), where the existence of an 
informal labor market ensures that any unemployment is voluntary, but it does not disaggregate commodities into tradables and non-tradables.

Effective management of foreign exchange parities is a perennial challenge for many developing countries, often with political ramifications related to sectoral wage differentials. The findings that devaluation can appreciate the real exchange rate and worsen the trade balance (Helpman, 1977) and may be contractionary (Krugman \& Taylor, 1978) have been examined extensively, for instance, by Mejía-Reyesab et. al. (2010), Shieh (2009), Frankel (2005), Agénor and Aizenman (1999), Kamin and Klau (1998) and Edwards (1986). This paper contributes to the existing literature by showing that the job search premium and the relative sizes of the informal and formal sectors play an important role in shaping the response of the economy to a devaluation of its currency. Since developing economies differ in respect to these structural elements, their consideration can account for differences in outcomes across economies.

It is well understood that real exchange rate changes are caused by real shocks often driven by productivity or other shocks. We show that a reduction in the job search premium itself has an independent effect on the real exchange rate, causing it to depreciate. Hence, efforts by governments and multilateral agencies to institute mechanisms to bring about reductions in the search premium by increasing the efficiency of labor exchange also serve to enhance international competitiveness. In any event, to the extent that the process of economic development is usually accompanied by such a reduction in the search premium, it will have a beneficial impact on the evolution of real exchange rates. To our knowledge this issue has not been investigated elsewhere.

A theoretical model embodying the specific characteristics mentioned above is provided in the next section. In section 3 , the effects of a shock in the price of tradable goods caused by devaluation are analyzed. The consequences of a shock in the job search premium are the subject of section 4 . Section 5 provides concluding comments.

\section{A Model of a Small Open Economy with a Partial Real Wage Floor}

A small, open, developing economy produces tradable $(t)$ and non-tradable $(n)$ goods. Following the scheme in Fiess (2010) and Agénor and Aizenman (1999), tradable goods are produced in the formal sector and non-tradable goods are produced in the informal sector. This output market-labor market assignment is notional, suggestive of developing country practices and an approximation that captures the broad realities and is, of course, not strictly true in practice (Note 1). In the formal sector, the wage in terms of a consumption basket is exogenously given and the demand for tradable goods is infinitely elastic at given world prices; any excess demand is met by changes in the trade balance. Given the binding real wage floor in the $t$-sector, employment is determined by labor demand. In contrast, the market for non-tradables clears domestically and the informal $n$-sector wage adjusts freely to clear the informal labor market.

\subsection{The Output Market}

If $e(\cdot)$ is the minimum expenditure required to attain utility $\hat{v}$ at prices $p_{i}$, then the wage restriction in the $t$-sector is:

$$
W_{t} \geq e\left(p_{t}, p_{n}, \widehat{v}\right)
$$

where $W_{i}$ is the nominal wage in sector $i$ and $P=p_{t}^{\alpha} p_{n}^{1-\alpha}$ is the aggregate price index, where $\alpha$ is the share of tradables in consumption. Assume the wage restriction is binding, excludes money illusion, and is of the form $W_{t}=\omega_{t}(\hat{v}) p_{t}^{\alpha} p_{n}^{1-\alpha}$. Then real consumption wage floor in the formal sector that ensures minimum utility $\hat{v}$ is $\omega_{t}(\hat{v})=\widehat{\omega}_{t}=W_{t} / p_{t}^{\alpha} p_{n}^{1-\alpha}$. Define $\omega_{n}=W_{n} / p_{t}^{\alpha} p_{n}^{1-\alpha}$ as the $n$-sector consumption wage. Assume that the wage floor is binding.

Let the exchange rate $x$ be fixed by policy; $x$ is the domestic currency price of foreign currency. The home currency price of tradable goods is $p_{t}=x \bar{p}_{t}$ where $\bar{p}_{t}$ is the foreign currency price. Since for a small country the foreign currency price of tradable goods exogenous, choose units of the tradable good so that $\bar{p}_{t}=1$. Then $x$ is the domestic currency price of both the foreign currency and the tradable good. Define the real exchange rate-the relative price of traded goods-as $p=x / p_{n}$. An increase in $p$ denotes a real depreciation of the domestic currency.

Employers in sector $i$ choose labor $L_{i}$ to maximize profits subject to the production function $S_{i}=L_{i}^{\beta_{i}}$. The first-order conditions are $S_{n}^{\prime}\left(L_{n}\right)=\omega_{n} p^{\alpha}$ and $S_{t}^{\prime}\left(L_{t}\right)=\widehat{\omega}_{t} p^{\alpha-1}$. Commodity supply curves are given by:

$$
S_{n}\left(p, \omega_{n}\right)=\left(\frac{\beta_{n}}{\omega_{n} p^{\alpha}}\right)^{\frac{\beta_{n}}{1-\beta_{n}}}
$$




$$
S_{t}\left(p ; \bar{\omega}_{t}\right)=\left(\frac{\beta_{t} p^{1-\alpha}}{\widehat{\omega}_{t}}\right)^{\frac{\beta_{t}}{1-\beta_{t}}}
$$

The demand for $\operatorname{good} j(j=n, t)$ is $D_{j}=D_{j}^{P}\left(p_{t}, p_{n}, y\right)+D_{j}^{G}$, where $D_{j}^{P}$ and $D_{j}^{G}$ are private and government demands, respectively. With $Y$ and $T$ denoting the GDP and tax, respectively, the local currency disposable income is $y=Y-T=\sum_{j} p_{j} S_{j}(\cdot)-T$. Let $\bar{y}=y / x$ be the disposable income in foreign currency units. Then in view of (1a) and $1(\mathrm{~b})$, being homogenous of degree zero, the demand function for $\operatorname{good} j(j=n, t)$ can be expressed as:

$$
D_{j}\left(p, \omega_{n}\right)=D_{j}^{P}\left(p, \bar{y}\left(p, \omega_{n}\right)\right)+D_{j}^{G}
$$

where

$$
\bar{y}\left(p, \omega_{n}\right)=p^{-1} S_{n}\left(p, \omega_{n}\right)+S_{t}\left(p ; \widehat{\omega}_{t}\right)-x^{-1} T
$$

Goods market equilibrium requires that the output market for $n$-goods clear domestically as given in (4a) below. For $t$-goods, however, any excess demand is met by reducing the domestic currency trade balance $B$. This condition is given by (4b), where $x$ also represents the domestic currency price of tradable goods.

$$
\begin{gathered}
S_{n}\left(p, \omega_{n}\right)-D_{n}^{P}\left(p, \omega_{n} ; x\right)-D_{n}^{G}=0 \\
S_{t}\left(p ; \widehat{\omega}_{t}\right)-D_{t}^{P}\left(p, \omega_{n} ; x\right)-D_{t}^{G}=x^{-1} B
\end{gathered}
$$

Following Helpman (1977) we assume that there is no demand for financial assets in this economy and consequently we omit the wealth effects of the corresponding change in net foreign assets in the balance of payments accounts. In view of this assumption, Walras' Law and (4) imply that the trade balance denominated in the domestic and foreign currencies, respectively, are given by (5a) and (5b) below:

$$
\begin{aligned}
& B=T-\left(p_{n} D_{n}^{G}+x D_{t}^{G}\right) \\
& \bar{B}=x^{-1} T-\left(p^{-1} D_{n}^{G}+D_{t}^{G}\right)
\end{aligned}
$$

\subsection{The Labor Market}

Labor demands in the two sectors are obtained by inverting the first-order conditions noted above:

$$
\begin{gathered}
L_{n}^{d}\left(p, \omega_{n}\right)=\left(\frac{\beta_{n}}{\omega_{n} p^{\alpha}}\right)^{\frac{1}{1-\beta_{n}}} \\
L_{t}^{d}\left(p ; \widehat{\omega}_{t}\right)=\left(\frac{\beta_{t} p^{1-\alpha}}{\widehat{\omega}_{t}}\right)^{\frac{1}{1-\beta_{t}}}=L_{t}(p)
\end{gathered}
$$

Note that in (6a) and (6b), $p=x p_{n}^{-1}$ is the real exchange rate; the demand for labor in each sector is an increasing function of the relative price of the output of that sector. Also note that with a binding wage restriction, employment in the $t$-sector $L_{t}$ is determined by the demand side alone, but in the informal $n$-sector, it is a function of both labor demand and supply.

Labor supply to the informal sector is modeled after Pinera and Selowsky (1978) where informal sector workers have some probability of gaining coveted formal sector jobs, but if they opt not to work and devote the period to job search instead, the probability of getting a formal sector job increases. Given there exists this search premiumpresumed to depend on custom, technology and policy - the marginal worker balances the benefit of the informal sector wage against the cost of facing a reduced probability of obtaining a formal sector job. Assume the economy's endowment of labor is $\bar{L}$. Each of $\left(\bar{L}-L_{t}\right)$ workers rationed out of the $t$-sector may follow one of two strategies:

(1) Accept an informal $n$-sector job in the current period and work there until a $t$-sector job is offered with probability $\pi$ of generating this offer in any period. Let the expected payoff from this strategy be $R_{1}$.

(2) Devote the present period exclusively to searching for a $t$-sector job, increasing the probability of success from $\pi$ to $\varphi \pi, \varphi>1$ being the job search premium. In the next period, he will be employed in the $t$-sector if 
successful or in the informal sector if unsuccessful. Let the expected payoff from this strategy be $R_{2}$.

As noted in Pinera and Selowsky (1978), if $\delta$ and $T$ respectively denote the real rate of discount and time, then the expected payoffs from these two strategies, $R_{1}$ and $R_{2}$, are (Note 2):

$$
\begin{aligned}
& R_{1}=\omega_{n 0}+\sum_{T=1}^{\infty} \frac{\widehat{\omega}_{t T}-\left(\widehat{\omega}_{t T}-\omega_{n T}\right)(1-\pi)^{T}}{(1+\delta)^{T}} \\
& R_{2}=\sum_{T=1}^{\infty} \frac{\widehat{\omega}_{t T}-\left(\widehat{\omega}_{t T}-\omega_{n T}\right)(1-\varphi \pi)(1-\pi)^{T-1}}{(1+\delta)^{T}}
\end{aligned}
$$

The marginal worker in the $n$-sector is in equilibrium when the payoffs from these two strategies are equal, i.e., $R_{1}=R_{2}$. Now, under the assumption that wages in both sectors are expected to grow at the same constant rate $g$, and further, that the discount rate $\delta>g$, (Note 3 ) the equality of payoffs (7a) and (7b) occurs when:

$$
\pi=\frac{k \omega_{n}}{(\varphi-1) \widehat{\omega}_{t}-\varphi \omega_{n}}
$$

It may be seen from equation (8a), where $k$ is a positive constant, that since $\varphi$ and $\widehat{\omega}_{t}$ are exogenously determined, the informal worker's equilibrium $\left(R_{1}=R_{2}\right)$ stipulates an implicit relationship between $\pi$ and the informal sector wage $\omega_{n}$. Now, $\pi$ itself depends upon labor market variables such as the number of vacancies in the $t$-sector, the number of aspiring potential $t$-sector workers, and their employment status. We assume that $t$-sector offers arise as firms strive to fill vacancies $(V)$ caused by normal turnover and growth. Since employment in the $t$-sector is demand-determined, $t$-sector firms will successfully fill the $V$ vacancies. They will do so by absorbing $\pi L_{n}^{s}$ workers engaged in the $n$-sector production and $\varphi \pi U$ of the unemployed, but successful, searchers. Thus, $V=\pi L_{n}^{s}+\varphi \pi U=\pi\left(L_{n}^{s}+\varphi U\right)$, implying that in addition to (8a), $\pi$ must also satisfy:

$$
\pi=\frac{V}{L_{n}^{s}+\varphi U}
$$

Further note that the consistency condition in the labor markets requires that the $\left(\bar{L}-L_{t}\right)$ workers excluded from the $t$-sector be accounted for either as $n$-sector workers or as unemployed $(U)$, i.e.:

$$
\bar{L}-L_{t}=L_{n}^{s}+U
$$

Equations (8a), (8b) and (9) can be used to obtain the informal or $n$-sector labor supply function. Eliminating $\pi$ from (8a) and (8b), and using the resulting expression and (9) to then eliminate $U$ yields the following $n$-sector labor supply function:

$$
L_{n}^{s}\left(p, \omega_{n}\right)=a_{0}-a_{1}\left(\frac{\bar{\omega}_{t}}{\omega_{n}}\right)+a_{2}\left(\bar{L}-L_{t}(p)\right)
$$

In equation (10) $a_{0}=a_{1} a_{2}>0, a_{1}=(V / k)>0$ and $a_{2}=\varphi /(\varphi-1)>1$. This relationship specifies how many of the workers rationed out of the $t$-sector are willing to work in the $n$-sector at different wage rates. Note that $L_{n}^{s}(\cdot)$ is increasing in $\omega_{n}$ and decreasing in $p$ (the real exchange rate is $p=x p_{n}^{-1}$ ). In this labor supply function, it is instructive to single out for consideration the coefficient $a_{2}$ which plays a significant role in analysis below. Note $a_{2}=-\partial L_{n}^{s} / \partial L_{t}>1$, implying that when the $t$-sector hires one worker, more than one worker leaves the $n$-sector. Let us call this effect, captured by $a_{2}$, the magnification effect of $t$-sector employment.

\subsection{General Equilibrium and Stability}

Define $E_{L}$ and $E_{n}$ as quantity imbalances in the informal labor market and non-tradable output market, respectively. The general equilibrium is given by the following market clearance conditions:

$$
\begin{gathered}
E_{L}\left(\omega_{n}, p\right)=L_{n}^{d}\left(\omega_{n}, p\right)-L_{n}^{s}\left(\omega_{n}, p\right)=0 \\
E_{n}\left(\omega_{n}, p ; x\right)=S_{n}\left(\omega_{n}, p\right)-D_{n}\left(p, \bar{y}\left(\omega_{n}, p ; x\right)\right)=0
\end{gathered}
$$


Equations (11) and (12) provide two independent equations in two unknowns, $\omega_{n}$ and $p$. Let the equilibrium be denoted by $\left(\omega_{n}^{*}, p^{*}\right)$. Then substitution in equations (1a;b), (3a;b) and (9) yield the equilibrium values of the relevant endogenous variables: $S_{n}, S_{t}, L_{n}, L_{t}$ and $U$. The local asymptotic stability of the equilibrium is guaranteed if the pure substitution effect of a relative output price change on the private demand for non-traded goods dominates the effect of a change in disposable income caused by the same price change (Note 4), i.e., $\partial D_{n}^{P} / \partial p+\left(\partial D_{n}^{P} / \partial \bar{y}\right)(\partial \bar{y} / \partial p)>0$. This condition ensures that the excess supply of $n$-goods is a negative function of $p$ and it is assumed to hold for each of the propositions in the following sections. The parameter restrictions implied by this condition are derived in Appendix I.

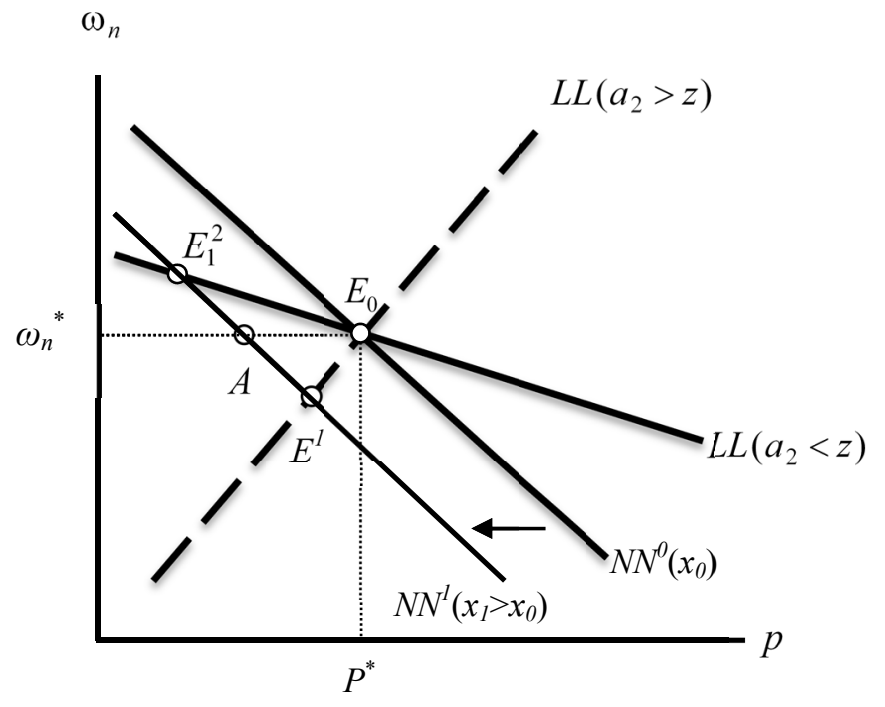

Figure 1. General equilibrium and the effects of devaluation

In Figure 1 the loci $E_{L}\left(p, \omega_{n}\right)=0$ and $E_{N}\left(p, \omega_{n} ; x_{0}\right)=0$ are given by $L L$ and $N N^{0}$ respectively. Graphically, stability boils down to the requirement that $L L$ cross $N N$ from below. The slope of the $L L$ curve may be negative or positive depending upon the balance of two structural features of the economy. Firstly, consider the effect of a given reduction in the price of tradable goods, i.e., in the real exchange rate $p$, on the supply of labor in the $n$-sector. The increase in $n$-sector labor supply per unit reduction in $t$-sector employment is given by the magnification effect $a_{2}$. Thus, the larger is $a_{2}$, the larger will be the increase in $n$-sector labor supply. Secondly, consider the $n$-sector labor demand. Define the effective size of the informal sector relative to the formal sector as $z=\left(\eta_{n p} L_{n} / \eta_{t p} L_{t}\right)$, where $\eta_{i p}$ is the (absolute value of) $i$-sector labor demand elasticity with respect to the relative price. The magnitude of $z$ determines the increase in the desired demand for labor by $n$-sector firms per unit layoff of workers by $t$-sector firms. If $a_{2}>z$, the increase in labor supply dominates the increase in labor demand, $\omega_{n}$ decreases as $p$ decreases, and $L L$ is positively sloped. Conversely, if $a_{2}<z$, then $L L$ is negatively sloped. Hence the slope of $L L$ is of $\operatorname{sgn}\left(a_{2}-z\right)$.

In the output market, a given decrease in the real exchange rate $p$ increases $S_{n}(\cdot)$. Holding disposable income $\bar{y}$ constant, the demand for non-tradables $D_{n}^{P}(\cdot)$ decreases and creates an excess supply of $n$-sector output. But the decrease in $p$ also affects income. Since $\bar{y}=p^{-1} S_{n}(\cdot)+S_{t}(\cdot)$, and $p^{-1} S_{n}(\cdot)$ increases while $S_{t}(\cdot)$ decreases as $p$ decreases, $\bar{y}$ may decrease or increase. If $\bar{y}$ decreases then the direct effect of the reduction in $p$ on the demand for $n$-goods is reinforced by its negative income effect. If $\bar{y}$ increases, the effect of income on $D_{n}^{P}(\cdot)$ is positive, but under parameter restrictions for stability discussed above, the total effect of a decrease in $p$ is also to decrease the demand for non-tradables. Therefore, when $p$ decreases, an increase in $\omega_{n}$ is required to reduce the excess supply of non-tradables and consequently $N N$ is negatively sloped. 


\section{Effects of Devaluation}

In this section we examine how this small open economic with dual labor markets and fixed exchange rate responds to a policy-induced change in the exchange rate. Findings of particular interest are that devaluation always leads to an appreciation of the real exchange rate, that the balance of the magnification effect arising from the job search premium and the relative effective sizes of the informal and formal sectors determine the direction of change in the sectoral wage differential, and that devaluation may cause the real output to contract. It should be noted that in this atemporal model, following the analysis in Helpman (1977), we have assumed there is no demand for financial assets and consequently ignore the effects of wealth changes pursuant to changes in net foreign assets resulting from the trade imbalance; nominal devaluation is assumed to have real effects through its impact on real wages.

Proposition 1: A devaluation results in the following changes:

(i) $d p / d x<0$;

(ii) $\operatorname{sgn}\left(d \omega_{n} / d x\right)=\operatorname{sgn}\left(z-a_{2}\right)$;

(iii) $d L_{n} / d x>0$;

(iv) $d L_{t} / d x<0$;

(v) $d U / d x<0$ if $z \geq 1$;

(vi) $d B / d x<0 ; d \bar{B} / d x<0$.

Proof: See Appendix II.

Discussion: Helpman (1977) has shown that in the presence of an economy-wide floor, the real exchange rate will appreciate in the face of a nominal devaluation if the effective size of the $n$-sector (though defined differently) exceeds the marginal propensity to consume $n$-goods. We find that with a partial wage floor, devaluation always causes the real exchange rate to appreciate ( $p$ decreases): the devaluation of the home currency is outweighed by the increase in the price of non-tradables so that the relative price of tradables decreases in equilibrium. As a point of reference, at the initial equilibrium $\left(\omega_{n}^{*}, p^{*}\right)$ let $a_{2}=z$ so that in Figure 1 the $L L$ curve is flat and the labor market clears at $\omega_{n}^{*}$ for any nominal exchange rate. The stability condition given above ensures that an increase in $x$ reflecting the devaluation increases the demand for non-tradables. However, at $\left(\omega_{n}^{*}, p^{*}\right)$ the supply of non-tradables is unchanged and therefore, at the initial equilibrium, there exists an excess demand for $n$-goods. With a given $\omega_{n}^{*}$ (as implied by the assumption that $a_{2}=z$ ) the entire burden of adjustment in the output market falls on the real exchange rate $p$ : it must appreciate. And as $p$ decreases, $S_{n}\left(\omega_{n}^{*}, p\right)$ increases per (1a) to clear the market for non-tradables. In Figure 1, $N N^{0}$ shifts to $N N^{1}$ and the output market moves from initial equilibrium $E_{0}$ to $A$.

The real exchange rate appreciation affects both the supply and the demand for labor. The ensuing contraction of employment in the $t$-sector increases $L_{n}^{s}$, which is larger the larger is the magnification effect $a_{2}$. But the appreciation also increases $L_{n}^{d}$. Now, if the magnification effect of the change in $t$-sector employment $\left(a_{2}\right)$ is larger than the effective labor absorption by informal sector firms $(z)$ then the increase in labor supply $L_{n}^{s}$ dominates the increase in labor demand $L_{n}^{d}$, and $\omega_{n}$ declines. Because the reduction in $\omega_{n}$ also increases the supply of $n$-goods relative to demand, the real exchange rate appreciation required for output market clearance is smaller than in the previous case: the equilibrium shifts from $E_{0}$ to $E_{1}^{1}$ rather than to $A$. Regardless of the effect on $\omega_{n}$, informal (formal) sector employment and output will increase (decrease). Conversely, if $a_{2}<z$, then the equilibrium shifts to $E_{1}^{2}$.

Consequently the sectoral wage gap given by $\widehat{\omega}_{t} / \omega_{n}$ can increase or decrease according as $a_{2}>=<z$. All else constant, countries with smaller informal sectors (low $z$ ) are more likely to see an increase in the sectoral wage gap. The effect on unemployment is less clear. If $z>1$, unemployment decreases; otherwise it may increase or decrease. It is clear, though, that if $z>a_{2}$ then $z>1$ since $a_{2}>1$. An increase in $\omega_{n}$ is accompanied by a decrease in unemployment. The appreciation of the real exchange rate $p$, i.e., the decrease in the relative price of $t$-goods, causes an excess demand for $t$-goods that is met by a deteriorating balance of trade. Since $x$ increases and $p$ decreases, it can be seen by inspection of equations (5a) and 5(b) that without fiscal policy contraction the devaluation will worsen the trade balance.

The real exchange rate appreciates in response to the devaluation because the proportionate increase in the price of non-traded goods exceeds that of traded goods. So the aggregate price level increases to a larger proportionate extent than the extent of the devaluation. That the devaluation is inflationary in this sense is, therefore, confirmed. Consider now its effect on real output. We already know that the output of non-tradables increase and tradables decrease due to devaluation regardless of whether output is measured in units of one good or the other so the most meaningful concept of real output is to consider it in terms of the typical consumption basket. In this sense the change in real 
output turns on both output and labor supply behavior. Define $\varepsilon_{j p}$ as the absolute value of the elasticity of supply of $\operatorname{good} j(j=n, t)$ with respect to the real exchange rate $p$, and $s_{n}$ as the share of non-tradables in total output.

Proposition 2: The devaluation will be contractionary if $z>a_{2}$ and $s_{n} \leq\left(1-\alpha+\varepsilon_{t p}\right)\left(1+\varepsilon_{n p}+\varepsilon_{t p}\right)^{-1}$. It will be expansionary if $z<a_{2}$ and $s_{n} \geq\left(1-\alpha+\varepsilon_{t p}\right)\left(1+\varepsilon_{n p}+\varepsilon_{t p}\right)^{-1}$.

Proof: See Appendix III.

Discussion: The results indicate that if the effective size of the informal sector $(z)$ is larger than the magnification effect $\left(a_{2}\right)$ but the share of non-tradables in GDP is smaller than the particular configuration of the price elasticities of output supply $\varepsilon_{j p}$ (in absolute values) and the share of tradables in consumption $\alpha$, then devaluation will be immiserizing. This analysis therefore provides new insights into the causes of the possible contractionary effects of devaluation in the developing country context by showing that the specific structural features of the devaluing country plays a determining role. It generally follows that the qualitative impacts of devaluation will vary across developing countries since they likely differ by these structural features along a spectrum.

\section{Effects of a Change in the Job Search Premium}

Since the job search premium $\varphi>1$ reflects the efficiency of labor exchange, it is to be expected that developing countries at different stages of development or through time will see the search premium decline as labor market practices change to market norms and domestic labor markets become integrated. A policy-induced reduction in the cost of information through the creation of employment exchanges or penetration of information technology could lead to such changes. Stated differently, broader dispersion of information and exchange mechanisms are likely to reduce the relative attractiveness of unemployment as an equilibrium state for workers seeking formal sector jobs. What effects ensue from a decline in the search premium?

Proposition 3: A change in the job search premium $\varphi$ has the following effects:

(i) $d p / d \varphi<0$;

(ii) $d \omega_{n} / d \varphi>0$;

(iii) $d L_{n} / d \varphi<0$;

(iv) $d L_{t} / d \varphi<0$;

(v) $d U / d \varphi>0$;

(vi) $d B / d \varphi<0 ; d \bar{B} / d \varphi<0$.

Proof: See Appendix IV.

Discussion: Other things given, a reduction in $\varphi$ reduces the expected returns from the strategy of searching for a formal sector job without working in the informal sector, and causes an excess supply of labor in the informal sector at the initial relative prices. In terms of (10) it increases the magnification effect $a_{2}$, and of those workers rationed out of the formal sector, fewer choose unemployment over informal sector employment; the new labor market equilibrium calls for a downward shift in the $L L$ curve. Overall, $\omega_{n}$ falls and the real exchange rate depreciates. Employment and output in the $t$-sector rise.

Even though the relative price of $n$-goods declines, the reduction in the informal sector wage is sufficiently large to lead to an increase in employment and output of $n$-goods. A decrease in the search premium causes the output of both sectors to increase: the existing slack in the labor market allows both sectors to expand, and consequently, unemployment declines. It bears notice that this type of institutional change in the context of developing countries is in essence a benign supply shock which has an independent effect on the real exchange rate, and by inference, on the trade balance, which, in this model increases in terms of both currencies. Our conclusion is thus a reassuring one that as economies become internally integrated, development occurs and labor market dualism declines, output will increase throughout the economy.

\section{Concluding Remarks}

This paper presents a model of a small open developing economy with dual labor markets producing tradable and non-tradable goods. Wage arbitrage is prevented by the exogenous imposition of a floor on the real consumption wage in the formal sector; there are no barriers to entry in the informal sector. Unemployment in this economy is voluntary since unemployed workers can increase the probability of obtaining a high-wage formal sector job through search activity relative to the probability of obtaining one while employed in informal sector production; job search carries a probability premium and is a rewarding activity. 
The results suggest differential responses among developing economies to adjustment policies such as a devaluation depending upon differences in structural factors such as the relative size of the non-traded goods sector and the job search premium. Devaluation, for instance, may be expansionary in some cases and contractionary in others. Likewise, unemployment and the sectoral wage differential may increase in some countries and decrease in others. These results offer an explanation of inter-country differences in economic performance and possibly of differences in political appetites and enthusiasm for undertaking policy reform. They also suggest that uniform adjustment policies for developing countries may not be warranted. We identify conditions under which such anomalous and divergent outcomes can occur.

We also find that the job search premium has an independent effect on the real exchange rate. As the job search premium declines, the real exchange rate depreciates and causes the tradable goods sector to expand. Hence, efforts by the government to institute mechanisms to bring about reductions in the search premium also serve to enhance international competitiveness. The increase in the output of traded goods does not come at the cost of non-traded goods: both sectors expand and unemployment declines, reflecting the effect of increased labor supply in the production of non-tradable goods due to the falling premium on search activity. Inevitably, this finding presents a case for policy action to hasten increased efficiency of labor exchange between segmented labor markets.

\section{Acknowledgments}

I thank participants at the annual meetings of the Eastern Economic Association and the Southern Economic Association for their comments on earlier versions of this paper. Any remaining errors are solely mine.

\section{References}

Agénor, P. R., \& Aizenman, J. (1999). Macroeconomic policy with segmented labor markets. Journal of Development Economics, 58, 277-296. http://dx.doi.org/10.1016/S0304-3878(98)00114-X

Brecher, R. A. (1974). Minimum wage rates and the pure theory of international trade. Quarterly Journal of Economics, 18, 98-116. http://dx.doi.org/10.2307/1881796

Edwards, S. (1986). Are devaluations contractionary? Review of Economics and Statistics, 68, 501-508. http://dx.doi.org/10.2307/1926028

Fiess, N. M., Fugazza, M., \& Maloney, W. F. (2010). Informal self-employment and macroeconomic fluctuations. Journal of Development Economics, 91, 211-226. http://dx.doi.org/10.1016/j.jdeveco.2009.09.009

Frankel, J. (2005). Mundell fleming lecture: Contractionary currency crashes in developing countries. IMF Staff Papers, 52, 149-194.

Harris, J. R., \& Todaro, M. P. (1970). Migration, unemployment, and development: A two-sector analysis. American Economic Review, 60, 126-142.

Helpman, E. (1977). Nontraded goods and macropolicy under a fixed exchange rate. Quarterly Journal of Economics, 91, 469-80. http://dx.doi.org/10.2307/1885978

Kamin, S. B., \& Klau, M. (1998). Some multi-country evidence on the effects of real exchange rates on output. Board of Governors of the Federal Reserve System International Finance Discussion Papers, No. 611. http://dx.doi.org/10.2139/ssrn.96613

Krugman, P., \& Taylor, L. (1978). Contractionary effects of devaluation. Journal of International Economics, 8, 445456. http://dx.doi.org/10.1016/0022-1996(78)90007-7

Mejı'a-Reyesab, P., Osborna, D. R., \& Sensiera, M. (2010). Modeling real exchange rate effects on output performance in Latin America. Applied Economics, 42, 2491-2503. http://dx.doi.org/10.1080/00036840701858117

Pinera, S., \& Selowsky, M. (1978). The opportunity cost of labor and the returns to education under unemployment and labor market segmentation. Quarterly Journal of Economics, 92, 469-88. http://dx.doi.org/10.2307/1883154

Shieh, Y. (2009). The tight money effect of devaluation: An alternative interpretation of contractionary devaluation. Journal of Applied Business Economics, 4, 1-7.

\section{Notes}

Note 1. A counter-example to the proposed scheme may be non-plantation agriculture: overwhelmingly associated with the informal labor market, its output is also tradable. However, in view of agricultural commercial policies and tight government control of food prices in many developing countries, it is not 
invariably true that the domestic price of agriculture is determined by world prices. Further, most production in the informal sector is otherwise thought to be in services, and services are non-tradable in general. Consequently, we believe that the assumption of the model is a reasonable first approximation to developing country realities. However, anecdotal counter-examples, such as the production of rugs in the informal sector in some developing countries, do exist; the goods may be tradable and produced in industry segments with informal labor markets in the sense that norms and practices render any legal minimum wage unenforceable.

Note 2. With respect to (7a), note that in the current period 0 the worker earns wage $\omega_{n 0}$, in period 1 he expects to earn $\left[\pi \widehat{\omega}_{t 1}+(1-\pi) \omega_{n 1}\right]$, in period $2\left[\pi \widehat{\omega}_{t 2}+(1-\pi)\left[\pi \widehat{\omega}_{t 2}+(1-\pi) \omega_{n 2}\right]\right]$ and so on. The expression for $R_{1}$ is obtained by appropriately discounting and summing this stream of expected payoffs. The expression for $R_{2}$ in (7b) is similarly derived by setting $\omega_{n 0}=0$ and using the probability $\varphi \pi$ instead of $\pi$ to weight the formal $t$-sector earning in each period.

Note 3. This is an appropriate assumption for developing countries with high discount rates and low wage growth. Moreover, to the extent the discount factor is high the infinite horizon assumption is less strong and affords tractability.

Note 4. As shown in Appendix I, it requires that $c<\min \left(1, d_{n} \sigma_{n p}\right)$, where $c$ is the marginal propensity to consume $n$-goods, $d_{n}=D_{n}^{P} / D_{n}$ and $\sigma_{n p}$ the elasticity of demand for $n$-goods with respect to $p$ holding disposable income constant.

\section{Appendix}

Appendix I

Define the following terms:

$$
\begin{aligned}
& \frac{\partial \ln L_{n}^{d}}{\partial \ln \omega_{n}} \equiv-\eta_{n \omega}=-\frac{1}{1-\beta_{n}}<0 \\
& \frac{\partial \ln L_{n}^{d}}{\partial \ln p} \equiv-\eta_{n p}=-\frac{\alpha}{1-\beta_{n}}<0 \text {. Note } \eta_{n p}=\alpha \eta_{n \omega} \\
& \frac{\partial \ln L_{t}^{d}}{\partial \ln p} \equiv \eta_{t p}=\frac{1-\alpha}{1-\beta_{t}}>0 \\
& \frac{\partial \ln L_{n}^{s}}{\partial \ln \omega_{n}}=\frac{a_{1}\left(\overline{\omega_{t}} / \omega_{n}\right)}{L_{n}^{s}}>0 \\
& \frac{\partial \ln L_{n}^{s}}{\partial \ln p}=-a_{2} \eta_{t p} \frac{L_{t}}{L_{n}^{s}}<0 \\
& s_{n} \equiv p^{-1} S_{n} /\left(p^{-1} S_{n}+S_{t}\right) \text { : share of n-goods in GDP. } \\
& \frac{\partial \ln S_{n}}{\partial \ln \omega_{n}} \equiv-\varepsilon_{n \omega}=-\frac{\beta_{n}}{1-\beta_{n}}<0 \text {. Note } \varepsilon_{n \omega}=\beta_{n} \eta_{n \omega} \\
& \frac{\partial \ln S_{n}}{\partial \ln p} \equiv-\varepsilon_{n p}=-\frac{\alpha \beta_{n}}{1-\beta_{n}}<0 \text {. Note } \varepsilon_{n p}=\beta_{n} \eta_{n p} \\
& \frac{\partial \ln S_{t}}{\partial \ln p} \equiv \varepsilon_{t p}=\frac{(1-\alpha) \beta_{t}}{1-\beta_{t}}>0 . \text { Note } \varepsilon_{t p}=\beta_{t} \eta_{t p} \\
& \left.\frac{\partial \ln D_{n}^{P}}{\partial \ln p}\right|_{\bar{y}=\bar{y}_{0}} \equiv \sigma_{n p}>0
\end{aligned}
$$

$c=p^{-1} \partial D_{n}^{P} / \partial \bar{y} \equiv$ marginal propensity to consume $n$.

$d_{n} \equiv D_{n}^{P} /\left(D_{n}^{P}+D_{n}^{G}\right)=D_{n}^{P} / D_{n}$, the share of private demand in total demand for $\mathrm{n}$ goods. 
Let $\dot{p}=a\left\{S_{n}(\cdot)-D_{n}(\cdot)\right\}=a E_{N}\left(p, \omega_{n} ; x\right), \quad \dot{\omega}_{n}=b\left\{L_{n}^{d}(\cdot)-L_{n}^{s}(\cdot)\right\}=b E_{L}\left(p, \omega_{n}\right) \quad$ where $a, b>0$, and $\quad\left(p^{*}, \omega_{n}^{*}\right)$ be the equilibrium. Let $J=\left\{j_{k l}\right\}$ be the Jacobian:

$$
J=\left[\begin{array}{ll}
\frac{\partial E_{L}\left(p^{*}, \omega_{n}^{*}\right)}{\partial \omega_{n}} & \frac{\partial E_{L}\left(p^{*}, \omega_{n}^{*}\right)}{\partial p} \\
\frac{\partial E_{N}\left(p^{*}, \omega_{n}^{*}\right)}{\partial \omega_{n}} & \frac{\partial E_{N}\left(p^{*}, \omega_{n}^{*}\right)}{\partial p}
\end{array}\right]
$$

where $j_{11}=-\left(\eta_{n \omega} L_{n}+a_{1} \frac{\widehat{\omega}_{t}}{\omega_{n}}\right)<0 ; \quad j_{12}=\left(a_{2}-z\right) \eta_{t p} L_{t}$

$$
j_{21}=-(1-c) \varepsilon_{n \omega}<0 ; \quad j_{22}=-\left\{(1-c) \varepsilon_{n p}+\left(d_{n} \sigma_{n p}-c\right)+\frac{\left(1-s_{n}\right)}{s_{n}} c \varepsilon_{t p}\right\}
$$

By application of the Liapunov theorem, the system in (11)-(12) is locally asymptotically stable if $\operatorname{tr}(\mathrm{J})<0$ and $|J|>0$. The trace condition is satisfied if $c<\min \left(1, d_{n} \sigma_{n p}\right)$. Under this parameter restriction, noting that $\varepsilon_{n p}=\beta_{n} \eta_{n p}$ and $\varepsilon_{n \omega}=\beta_{n} \eta_{n \omega},|J|>0$ as given in (I.2) below:

$$
\begin{aligned}
|J|= & \eta_{n \omega} L_{n}\left[\left(d_{n} \sigma_{n p}-c\right)+\frac{\left(1-s_{n}\right)}{s_{n}} c \varepsilon_{t p}\right]+a_{1} \frac{\widehat{\omega}_{t}}{\omega_{n}}\left[(1-c) \varepsilon_{n p}+\left(d_{n} \sigma_{n p}-c\right)+\frac{\left(1-s_{n}\right)}{s_{n}} c \varepsilon_{t p}\right] \\
& +(1-c) \varepsilon_{n \omega} a_{2} \eta_{t p} L_{t}>0
\end{aligned}
$$

Appendix II

Let $\hat{z}=d z / z$. Totally differentiating equations (11) and (12) with respect to the nominal exchange rate $x$ yields:

$$
\left[\begin{array}{ll}
j_{11} & j_{12} \\
j_{21} & j_{22}
\end{array}\right]\left[\begin{array}{l}
\hat{\omega}_{n} \\
\hat{p}
\end{array}\right]=\left[\begin{array}{l}
0 \\
k
\end{array}\right] \hat{x}
$$

where $k=c p T / x^{2}>0$. Cramer's Rule yields

$$
\hat{\omega}_{n}=-k_{1} j_{12} \hat{x}
$$

where $k_{1}=k|J|^{-1}>0$. Since $j_{12}=\left(a_{2}-z\right) \eta_{t p} L_{t}, \operatorname{sgn}\left(\hat{\omega}_{n}\right)=\operatorname{sgn}\left(z-a_{2}\right)$. Further

$$
\hat{p}=k_{1} j_{11} \hat{x}<0
$$

Equation (6a) implies $\hat{L}_{n}=-\left[\eta_{n \omega} \hat{\omega}_{n}+\eta_{n p} \hat{p}\right]$. Upon substitution of (II.2) and (II.3), given $z=\eta_{n p} L_{n} / \eta_{t p} L_{t}$ :

$$
\hat{L}_{n}=k_{1}\left[a_{1}\left(\widehat{\omega}_{t} / \omega_{n}\right) \eta_{n p}+a_{2} \eta_{n \omega} \eta_{t p} L_{t}\right] \hat{x}>0
$$

Since $\hat{p}<0$ by (II.3), from equation (6b) we obtain:

$$
\hat{L}_{t}=\eta_{t p} \hat{p}<0
$$

Equation (9) implies $U=\bar{L}-L_{t}-L_{n}$. Since $d U / d x=-\left(d L_{t} / d x+d L_{n} / d x\right)$, use (II.4) and (II.5) to obtain:

$$
d U=-k_{2}\left[\left(a_{2}-1\right) z \eta_{t p} L_{t}+(z-1) \alpha a_{1}\left(\widehat{\omega}_{t} / \omega_{n}\right)\right] \hat{x}<0
$$

where $k_{2}=\alpha^{-1} k_{1}>0$. Because $a_{2}>1, d U<0$ if $z \geq 1$. Q.E.D.

Appendix III

The GDP is $Y=\sum_{j} p_{j} S_{j}(\cdot)$ and the price level is $P=p_{t}^{\alpha} p_{n}^{1-\alpha}$. Price deflated GDP can then be written as:

$$
\tilde{y}=p^{-\alpha} S_{n}(\cdot)+p^{1-\alpha} S_{t}(\cdot)
$$

Totally differentiating $\tilde{y}$ and collecting terms yields:

$$
d \tilde{y}=p^{-\alpha}\left\{\left[-\alpha p^{-1} S_{n}+\frac{\partial S_{n}}{\partial p}+(1-\alpha) S_{t}+p \frac{\partial S_{t}}{\partial p}\right] d p+\frac{\partial S_{n}}{\partial \omega_{n}} d \omega_{n}\right\}
$$


Upon expressing terms in III.2 in elasticity form, after rearrangement, we obtain:

$$
\hat{\tilde{y}}=\frac{p^{2-\alpha}}{x}\left\{\left[\left[(1-\alpha)+\varepsilon_{t p}\right]-s_{n}\left[1+\varepsilon_{n p}+\varepsilon_{t p}\right]\right] \hat{p}-s_{n} \varepsilon_{n \omega} \hat{\omega}_{n}\right\}
$$

Upon substituting from (II.2) and (II.3) we obtain:

$$
\hat{\tilde{y}}=-\frac{k_{1} p^{2-\alpha}}{\alpha x}\left\{\left[\left[(1-\alpha)+\varepsilon_{t p}\right]-s_{n}\left[1+\varepsilon_{n p}+\varepsilon_{t p}\right]\right] \lambda+\left[\left(1-\frac{a_{2}}{z}\right) s_{n} \varepsilon_{n p}\right]\right\} \eta_{n p} L_{n} \hat{x}
$$

where $\lambda=1+\frac{\alpha a_{1}\left(\widehat{\omega}_{t} / \omega_{n}\right)}{\eta_{n p} L_{n}}$. By inspection of (III.4), if $z>a_{2}$ and $s_{n}<\frac{1-\alpha+\varepsilon_{t p}}{1+\varepsilon_{n p}+\varepsilon_{t p}}$, then $\hat{\tilde{y}}<0$ and devaluation is contractionary. Q.E.D.

\section{Appendix IV}

Totally differentiating equation (11) and (12) with respect to $\varphi$ yields:

$$
\left[\begin{array}{ll}
j_{11} & j_{12} \\
j_{21} & j_{22}
\end{array}\right]\left[\begin{array}{l}
\hat{\omega}_{n} \\
\hat{p}
\end{array}\right]=\left[\begin{array}{c}
-\left(\bar{L}-L_{t}\right) a_{2}^{2} / \varphi \\
0
\end{array}\right] \hat{\varphi}
$$

The solutions are as follows:

$$
\hat{\omega}_{n}=-\frac{j_{22}\left(\bar{L}-L_{t}\right) a_{2}^{2}}{|J| \varphi} \hat{\varphi}>0
$$

since $j_{22}<0$ and

$$
\hat{p}=\frac{j_{21}\left(\bar{L}-L_{t}\right) a_{2}^{2}}{|J| \varphi} \hat{\varphi}<0
$$

since $j_{21}<0$. Because $\hat{L}_{n}=-\left[\eta_{n \omega} \hat{\omega}_{n}+\eta_{n p} \hat{p}\right]$ by (6a), and $\eta_{n p}=\alpha \eta_{n \omega}, \hat{L}_{n}=-\eta_{n \omega}\left[\hat{\omega}_{n}+\alpha \hat{p}\right]$, substitution of (IV.2) and (IV.3) yields, upon simplification:

$$
\hat{L}_{n}=-k_{3}\left(\left(d_{n} \sigma_{n p}-c\right)+\frac{\left(1-s_{n}\right)}{s_{n}} c \varepsilon_{t p}\right) \hat{\varphi}<0
$$

where $k_{3}=\frac{\eta_{n \omega}\left(\bar{L}-L_{t}\right) a_{2}^{2}}{|J| \varphi}>0$, and $\left(d_{n} \sigma_{n p}-c\right)>0$ by assumption as discussed in Appendix I. Since $\hat{p}<0$ by (IV.3), from equation (6b) we obtain:

$$
\hat{L}_{t}=\eta_{t p} \frac{j_{21}\left(\bar{L}-L_{t}\right) a_{2}^{2}}{|J| \varphi} \hat{\varphi}<0
$$

since $j_{21}<0$. Moreover, since $U=\bar{L}-L_{t}-L_{n}$ by (9), and $\hat{L}_{t}<0$ and $\hat{L}_{n}<0$ from (IV.4) and (IV.5),

$$
\frac{d U}{d \varphi}=-\left(\frac{d L_{t}}{d \varphi}+\frac{d L_{n}}{d \varphi}\right)>0
$$

Finally, since $\hat{p}=\hat{x}-\hat{p}_{n}<0$ and $\hat{x}=0, \hat{p}_{n}>0$. Thus by inspection of (5a) and (5b):

$$
\frac{d B}{d \varphi}<0
$$

Q.E.D.

\section{Copyrights}

Copyright for this article is retained by the author(s), with first publication rights granted to the journal.

This is an open-access article distributed under the terms and conditions of the Creative Commons Attribution license (http://creativecommons.org/licenses/by/3.0/). 